\title{
La Galgada: Arquitectura compleja precerámica y arte en tránsito a Chavín
}

\author{
Alberto Bueno Mendoza
}

\begin{abstract}
Resumen
Cuando estudiamos la arqueología y el arte de la Galgada lo hacemos con mucha simpatía hacia las culturas antiguas del Perú, porque se denota un entramado vital muy activo, tanto en las concepciones arquitectónicas muy técnicas y monumentales, como en la plasmación de sentimientos refi mados ceremoniosos en los interiores de los recintos con nichitos trapezoides parietales, la banqueta corrida en los segmentos inferiores de los paramentos internos, el metafórico horno - fogón céntrico en los pisos de los templos, etc., que connotan una época sentida de calma y sosiego apta para alcanzar la impasibilidad ritual o mística lejos de las difi cultades de la vida diaria.

Además, obliga a prepararnos para conocer el arte pre - Chavín de la Galgada plasmado en textiles pintados, huesos tallados, valvas de moluscos labrados pulidos finamente, piedras esculpidas, petroglifos figurativos y geométricos, etc., que representan diferentes esferas y expresiones gráficas conducentes a sus significados.

En este sentido, el simbolismo como tendencia artística convertida en ideas, confronta una categoría estilística enfrentada a la realidad empírica que busca en la tierra y en el aire un mundo de ideas diferentes consideradas como textos gráfi cos, los cuáles se encuentran en tránsito al convencionalismo metafórico simbolista del nuevo estilo de arte llamado Chavín.
\end{abstract}

Palabras claves: La Galgada, recintos con nichitos, pre - Chavín, petroglifos, textos gráficos, categoría estilística.

\begin{abstract}
COMPLEX PRE-CERAMIC ARCHITECTURE AND ART IN TRANSITION TO CHAVINN

The study of the archaeology and the art of Galgada brings great fondness towards the ancient cultures of Peru, because it presents rich and vivid cultural features, manifested both in the greatly monumental and technologically complex architectural concepts, and in the affects and emotion that appear to be embodied here in the particular archaeological material - the famous enclosures with trapezoidal parietal niches, the benches running in the lower segments of the internal walls, the "metaphorical" hearths in the centre of the floors of the temples, which designate the presence of a sacred, calm and tranquil dimension that is clearly delineated from the mundane.
\end{abstract}

Alberto Bueno Mendoza • abuenomendoza@hotmail.com, Universidad Nacional Mayor De San Marcos 
In addition, the article provides the reader with an introduction to the pre-Chavin art of Galgada that has been captured in painted textiles, carved bones, finely polished shellfish shells, sculpted stones, figurative and geometric petroglyphs, all of which present various graphic ideas and expressions in relation to their meanings.

In this sense, the symbolism presents a transformation of simple artistic traditions into complex visual systems, and represents confrontation between categories of graphic ideas that correlate to the ancient perceptions of the natural world and the world of different, abstract graphic ideas, which can be seen as a form of graphic text and as predecessors to the symbolic, metaphorical and greatly conventionalized styles of art of the subsequent Chavin period.

Keywords: La Galgada, enclosures with niches, pre-Chavin, petroglyphs, graphic texts, stylistic category

\section{Introducción}

Pallasca es la provincia altoandina más septentrional de la Región Ancash, perteneciente a la vertiente occidental de los Andes del norte peruano. Es un panorama constante en esta región encontrar un cañón silencioso con hondos agrietamientos, quebradas laterales secas y laderas desérticas empinadas. En las áreas donde baja un aguajal, riachuelo o riada, existen algún molle, algarrobo, guarango y en el lecho del río sauces, pájaro bobo, chillcos, juncos, totoras, etc., muy ralos. El cañón del río Chuquicara sirve de lindero entre las provincias de Pallasca-Ancash (margen izquierda) y Santiago de Chuco - La Libertad (margen derecha). El río es de aguas negras porque recorre un cauce con muchos afloramientos de antracita existente en ambas márgenes del cañón.

La fisiografía en el cañón del río Chuquicara es desértica y algunos trayectos sólo tienen la profundidad del río; la carretera que otorga acceso carrozable ha sido construida directamente en la gradiente de los cerros que lo encajonan; el panorama que se avista desde la localidad de Quiroz hasta Choloque muestra cerros de tierra grisácea, cerros de rocas sedimentarias y colinas moteadas por tierras negras, verduzcas, grises, amarillentas, rojizas y vetas carbonosas antracíticas de color negro azulado. El río se encuentra a 1100 msnm y es más profundo que el Cañón del Pato, irrigado por el río Santa.

Las prospecciones, excavaciones y estudios arqueológicos en el área de La Galgada (distrito de Tauca-Pallasca) permitieron descubrir nuevos estratos precerámicos con extraordinaria arquitectura monumental fechada en el tercer milenio antes de nuestra era; notables textiles pre-telar pintados y sin pintar, tumbas y cámaras mortuorias con los cadáveres “in situ”, cestería muy variada y bien técnica, arte lítico precerámico, tallados en concha, hueso, turquesa, crisocola, antracita, etc. y se estaba experimentando en el sitio una serie de maderas, fibras, cortezas y tintes de la mayor importancia.

Las excavaciones arqueológicas en el sitio han permitido disponer de una buena cantidad de datos para precisar la cronología; se elaboró una línea de tiempo por estratificación arqueológica de campo y fechados radiocarbónicos para contrastar el contexto de las asociaciones y establecer las correlaciones con otras áreas.

\section{La pirámide norte}


El sitio arqueológico está conformado por dos montículos: el Montículo Norte y el Montículo Sur (Fig. 1); se les asocian una serie de habitáculos pequeños en plantas ovaladas, circulares y rectangulares rodeando ambos promontorios.

Los trabajos revelaron que el Montículo Norte es una pirámide a base de cinco cuerpos escalonados de mayor antigüedad, en cuyo interior ocurren galerías de corto trayecto, recintos curvados con nichitos trapezoides, banqueta adosada a los muros, patio a desnivel y horno céntrico con ducto de aire para ventilación. Estos recintos excavados han sido fechados con radiocarbono (3200 a.C.) y cuya calibración dendrocronológica arrojó 2700 a.C. Por lo menos, los recintos del Montículo Norte funcionaron activamente por este tiempo y constituyen morfologías arquetípicas internas de estas pirámides con pozo, que despliegan planta cuadrada con esquinas curvadas.

En 1980 el trabajo se centró en conocer el contexto arquitectónico del Gran Templo Norte. La importancia fundamental de La Galgada se basa en parte en su arquitectura excepcionalmente fina y bien conservada. Estos edificios han prescrito un enfoque de excavación cuidadoso en el que se conservan los testimonios mínimos de cada período arquitectónico y sólo se extraen los escombros no recuperables y los rellenos expuestos. La conservación del monumento tiene la prioridad más alta del esfuerzo por investigar y registrar cuidadosamente los niveles más profundos de este importante complejo de templos.

El templo norte fue completamente renovado al menos cuatro veces. El primer nivel excavado, cuyo recinto curvado, I-11:D5, probablemente se remonta a alrededor de 3000 a.C., contiene un fogón ceremonial de un tipo encontrado también en Kotosh y Huaricoto, sólo que en La Galgada es más antiguo, el cual sigue siendo la estructura ceremonial típica en todo el precerámico de las tierras altas. En ese momento el nivel del piso estaba ya a 13 metros por encima de la base de la fachada noroeste. Es cierto que hay niveles más bajos y más antiguos por descubrir dentro del montículo. El templo fue completamente reconstruido en alrededor de 2700 a.C. con nuevos recintos ceremoniales en la parte superior y un enorme muro de esquina curvada circundante (Fig. 2). Varios siglos más tarde, las cámaras se llenaban de dos metros de relleno para soportar nuevos niveles de piso y se aumentó la elevación del muro circundante exterior. Los enormes muros externos del templo (Fig. 3) parecen haber servido para contener el relleno y hacer que el templo sea más alto e impresionante (16 metros).

Las excavaciones en el Montículo Norte se ejecutaron luego de metrar el área, dividir en cuadrículas su superficie alta y medir trincheras verticales en los lados en talud del monumento. Las temporadas en los años de 1979-1980 fueron dedicados a excavar este Montículo.

Los exámenes de superficie y las excavaciones demuestran que el Montículo Norte es un edificio de planta ligeramente rectangular con esquinas curvadas, elevación maciza y compacta, terminal alto (16 m. sobre el suelo) en morfología 


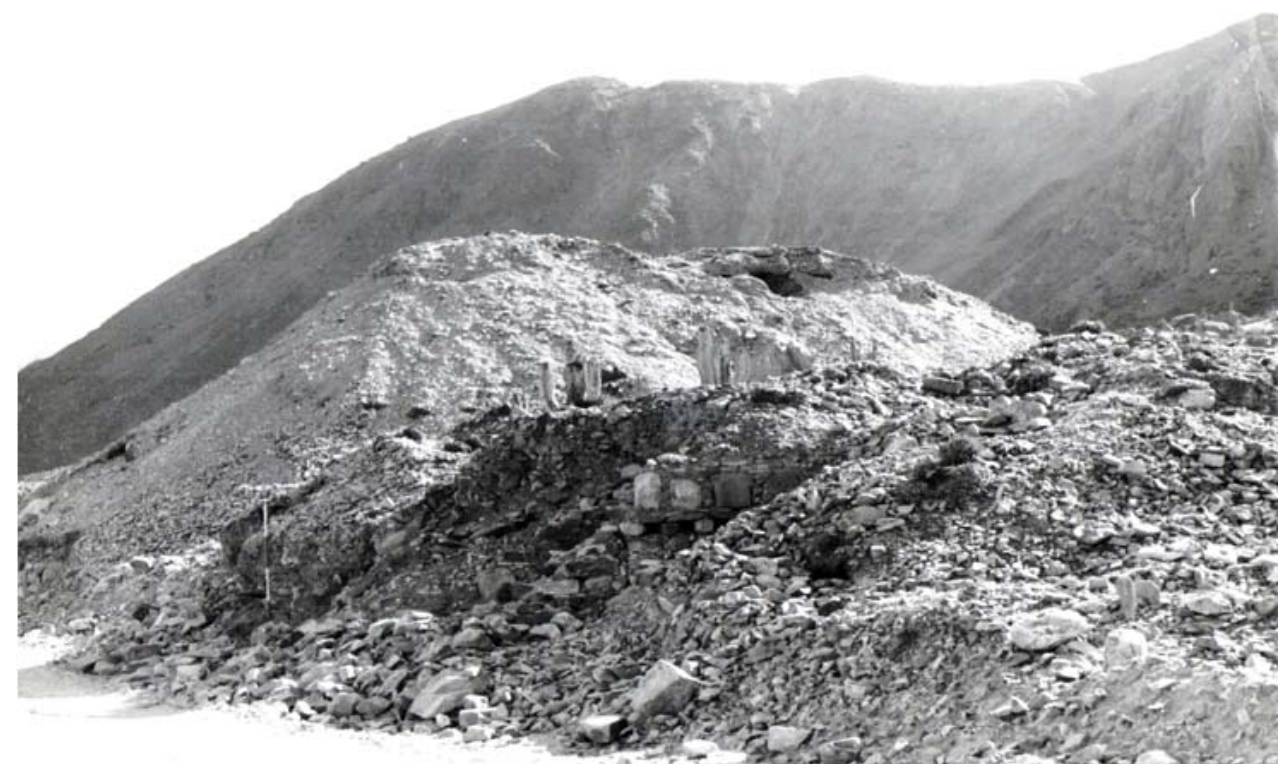

Figura 1. La Galgada: Los montículos arqueológicos Norte y Sur al inicio de las excavaciones en 1978.

"U” abierta al oeste, perfiles laterales platafórmicos y hacia el frente oeste se presenta frontal escalonado. Es un tipo de pirámide truncada, tiene perfil oeste escalonado y gran escalera frontal con pozo asociado igualmente frontal.

En el terminal alto se excavaron las cuadrículas M-1:D-5 del brazo derecho; la sección noroeste I-11:D5, la céntrica H-11:EF-10 de la "U” y el H-11:A-8 al pie del brazo izquierdo.

Hacia la parte delantera al pie del brazo derecho (M-11:D-5) descubrimos el recinto curvado noroeste (I-11:D5) con vestigios de tríos de nichitos trapezoides $(0,35 \mathrm{~m} \times 0,30 \mathrm{~m})$ promedio a medio destruir; la banqueta corrida adosada a los muros se muestra bien conservada y en su lado oeste se abre el vano de perfiles rectos. El diámetro norte-sur del espacio interno a nivel de la banqueta es de 3.80 metros, desagregado en 1metro de banqueta adosada a los muros y 2,80 metros de patio a desnivel en cuyo centro se inscribe un fogón sin ducto de ventilación; las esquinas del desnivel de la banqueta son rectilineales pero su fileteado es ligeramente curvado en los lados. Pintura blanca sobre aplanado con carga inerte de paja recubriendo muros y pisos, señala el mismo tratamiento técnico que los recintos análogos del Montículo Sur.

En el sector céntrico (H-11:EF-10) se excavó un segundo recinto curvado similar a I-11: D-5, pero de mayores dimensiones. Presenta una planta cuadrada con esquinas curvadas, banqueta de 1,20 metro de piso y 40 centímetros de desnivel para formar el patio central con horno inscrito; su diámetro este-oeste mide 2,20 


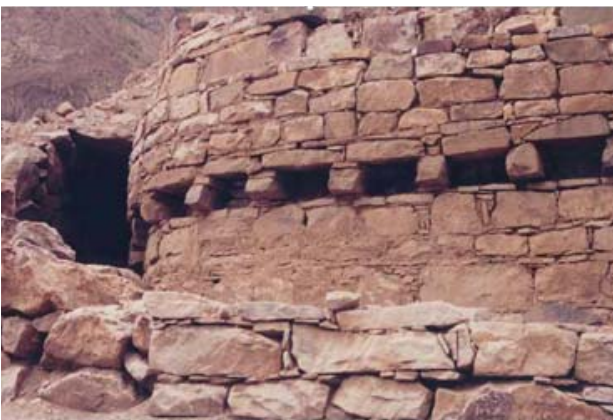

Figura 2. La Galgada: nichitos voladizos asociados a ingreso de una galería ubicada en la esquina curvada noroeste externa del Montículo Norte.

metros, lo cual significaría que este recinto es uno de los más amplios descubiertos y que su patio a desnivel también supera las medidas de otros estudiados (Fig. 5). La pintura blanca sobre aplanado terreo, llevando antiplástico de paja como carga inerte, está expuesta en segmentos interiores con cierto deterioro por filtraciones de lluvias. A partir de una pestaña de retiro, igual a otros recintos conocidos, existen las evidencias de cuatro nichitos trapezoidales por lado paramental pintados de blanco hasta sus fondos. Un hoyo cuadrado abierto ocurre en el piso de la banqueta en el ángulo sureste del recinto.

Al pie del brazo izquierdo del terminal alto excavamos otro recinto más pequeño que los anteriores descritos, pero de similar morfología; este recinto signado H-11:A-8 tiene adicionado un pequeño recinto lateral con banqueta y una tumba techada por maderas colocadas en disposición oblicua denominada G-11:I-5.

Inmediatamente colateral al recinto I-11:D-5 noreste descrito, entre éste y el muro norte envolvente de la pirámide, fue excavado un alargado recinto en morfología D nominado I-12:C-5; este recinto mide 8,20 m x 1,80 m a un desnivel de 0,40 m curvado. Todo esto está construido sobre relleno a la espalda del recinto central. El interior está pintado de blanco y conserva su pestaña de retiro, a partir de la cual se ven doce nichitos trapezoides; tales nichitos tienen espaciamiento paramental variado entre $0,35 \mathrm{~m}$ a $0,53 \mathrm{~m}$ de separación promediándose igualmente las dimensiones de éstos entre $0,25 \mathrm{~m}$ de base por $0,33 \mathrm{~m}$ de altura y 0,40 $\mathrm{m}$ en la base por 0,45 m de altura, caracterizándose por la diversidad de sus medidas. El recinto 


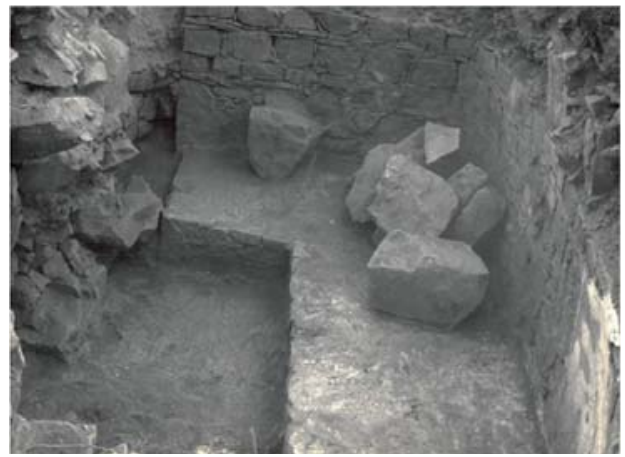

Figura 5. La Galgada: recinto H-11:EF-10 ubicado en la parte céntrica alta del Montículo Norte mostrando su banqueta adosada al muro derecho, según el perfil del vano abierto al norte.
$D$ tiene otro curvado en su lado este signado I-12:C-5; tiene banqueta corrida, pequeño patio con horno central, vano al oeste y tres nichitos en sus paramentos internos; un tabique murario con vano rectilineal los une, al parecer construido cuando fueron enterrados (Fig. 6).

Los recintos con nichitos trapezoides descritos tienen variación dimensional entre sí y se afirman estratigráficamente sobre un gran recinto curvado subyacente, subterráneo, que fue descubierto debajo de los rellenos y pisos de los recintos D y H-11: EF-10.

Debajo del recinto curvado I-11:D-5 existe 1.60 metros de relleno con torta de barro; en el límite inferior de este relleno se descubre la entrada de una galería parcialmente tapada por escombros sueltos deslizados desde afuera debido a un gran huaqueo antiguo. Huellas evidentes de haber sido profanada por depredadores no permite avisorar la solución del ingreso desde el exterior; sin embargo, el trayecto largo de la galería -entre el perfil del acceso hasta el fondo- mide 4,20 metros y su ancho inferior oscila entre $0,80 \mathrm{~m}$ desde el ingreso hasta $1,00 \mathrm{~m}$ en el fondo. Hacia 1,50 m del trayecto de la galería F-11:B-8, hacia el lado derecho del muro formante, se abre una ventana casi cuadrada $(0,60 \mathrm{~m} \mathrm{x} \mathrm{0,80} \mathrm{m)} \mathrm{de} \mathrm{ingreso} \mathrm{al} \mathrm{interior}$ del extraordinario recinto subyacente. La ventana interior tiene dintelamiento con palos de maguey colocados uno a cada extremo y en el centro otros dos maderos delgados naturales de algarrobo, fuertemente compactados con piedras chicas y barro, habiendo logrado amalgamar una verdadera mezcla capaz de sostener todo el peso (varias toneladas) de los rellenos y recintos superpuestos antes descritos.

Los muros laterales conformantes de la galería orientados de sur a norte son rústicos, constituidos por piedras grandes y lajas medianas asentadas con barro entremezcladas a piedrecillas y ripio; en cambio el gran muro del fondo está mejor elaborado al mostrar piedras con caras planas y aparejo en tránsito a ordenar hiladas pétreas regulares. La solución técnica de la galería fue lograda al límite de máxima utilización del material pétreo constructivo, pues los muros laterales se desplazan ligeramente al interior por sus bordes altos para sostener -a manera de ménsulaslargas vigas líticas cobertoras de la galería, tendidas en disposición este-oeste.

El recinto circular subyacente al cual otorga acceso la galería F-11:B-8 y ventana descrita, es tan amplio como el recinto H-11:EF-10 superpuesto. Piedras medianas rellenan un metro desde su piso, pero se infiere que debe ser análogo a los otros recintos conocidos; fina pintura blanca recubren sus muros internos; en el tercio medio de su paramento interno, de esquinas curvadas, lleva la pestaña de 


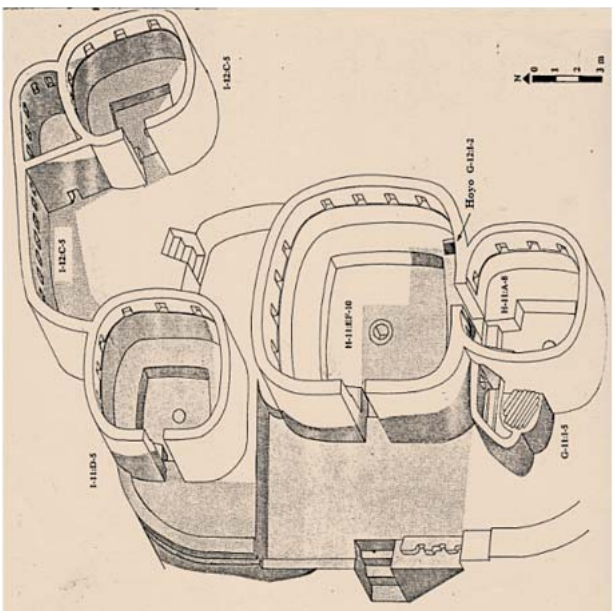

Figura 6. La Galgada: isométrica de los recintos descubiertos en la parte alta céntrica del Montículo Norte descritos y hacia el perfil oeste externo vemos la escalera alta céntrica.

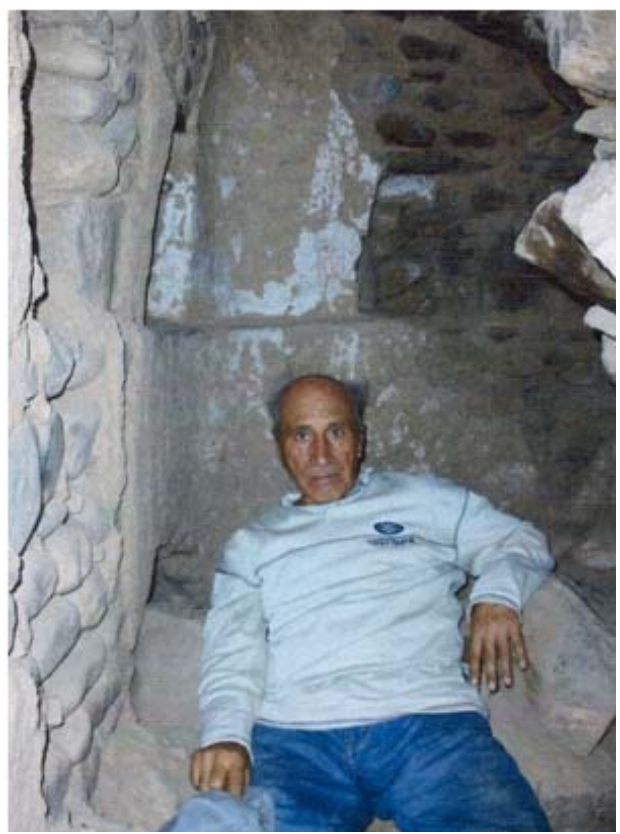

Figura 7. La Galgada, Montículo Norte: galería interior circular con nichitos trapeciales que se elevan a partir de la pestaña de retiro, revestidos de pintura blanca; [autor] sentado sobre las piedras caídas a nivel de piso original. A la izquierda la ventana interior de acceso descrita.

retiro con una cenefa de tres nichitos trapezoides por lado (Fig. 7); en su sección céntrica se construyó un gran pilar de sección cuadrada y 2 metros de diámetro, probablemente cuando decidieron enterrar el recinto; el pilar se proyecta macizo y muy consistente en gradual y compacto cimbramiento hacia los muros laterales del recinto para cubrirlo; es prácticamente semejante a la figura de un paraguas plano por arriba en significancia arquitectónica. Este verdadero ingenio, para su tiempo en los andes centrales, es una obra arquitectónica precerámica única en su género y el antecedente más arcaico de los apoyos concretos en la arquitectura arqueológica, pues sostiene varias toneladas superpuestas descritas.

Así, los trabajos revelaron que el Montículo Norte es una pirámide truncada con perfiles externos de cinco escalonados, en cuyo interior existen galerías de corto trayecto y recintos curvados con nichitos trapezoides, banquetas adosadas a los paramentos internos de los recintos, pequeños patios a desnivel y su horno inscrito centralizado llevando o no ducto de ventilación. Estos recintos excavados han sido fechados por radiocarbono, cuyos resultados calibrados por dendrocronología, respaldan cronología entre 2700 a.C. á 2300 a.C. Al menos, los recintos de la Pirámide Norte funcionaron activamente por este tiempo y constituyen morfologías 
internas de estos templos con pozo frontal que despliegan planta en cuadro con esquinas curvadas.

\section{Pirámide sur}

El Montículo Sur fue excavado en 1978; trabajando a nivel de la carretera actual y en el subsuelo de ésta descubrimos los recintos con nichitos análogos al Montículo Norte; el recinto cuadrado con esquinas curvadas está reconocido por la sigla D-11: C-3 y su carbón del horno centralizado en el pequeño patio fue fechado en $2380 \pm 164$ a.C. El recinto cuadrado con esquinas rectilineales (Fig. 8) signado C-11:I-3 fue fechado en 2260 \pm 187 a.C. Ambas fechas están calibradas por proceso dendrocronológico. Un tercer recinto con planta cuadrada y esquinas curvadas C-11: F-5 fue descubierto al sur del recinto cuadrado C-11:I-3. Tales recintos con nichitos trapezoides están revocados con aplanado de barro mezclado con carga inerte de paja y acabados a base de fina capa pictórica blanca; sus ductos para ventilación de los hornos tienen el tiro hacia abajo de la tábica de los vanos plasmados en solución rectilineal. Otros recintos curvados y cuadrados se han definido durante las excavaciones, los que se superponen verticalmente sobre rellenos de los inferiores convertidos en tumbas de morfología abotellada al ser enterrados.

Al pie del Montículo Norte descubrimos una gran tumba con tres cámaras en forma de E; la tumba E-11:J-7 tiene las cámaras funerarias en descenso por ligero desplazamiento hacia adelante, articuladas con escaleras verticales de tres escalones; sus tres secciones se encontraron tapadas fuertemente con su respectiva piedra plana plantada verticalmente y selladas con gruesa argamasa de barro. Al costado de la entrada de la tumba E-11:J-7 descubrimos otra tumba de una sola cámara, cuando se modificó un recinto de planta cuadrada y esquinas curvadas, con las mismas características de selladura; fue signada como tumba F-12:B-12 (Fig. 9) y albergaba tres cadáveres identificados como de un hombre y dos mujeres; estaban amortajados con telas de técnicas precerámicas y una red en técnica anudada; fueron depuestos sobre petates de totora y cubiertos con esteras de junco y/o totora indistintamente; una diadema de canastas elaboradas en fibras de junco o totora, mates, bolsas en técnica anillada envolviendo a canastas y dos piedras de río aplanadas, componían su ajuar funerario precerámico tardío (2302 \pm 323 a.C.).

En el Montículo Sur, los recintos D-11:C-3, C-11:I-3 y C-11:F-5 al rellenarse fueron convertidos en tumbas abotelladas (figura 10), al adicionarse construcción de muro al interior del recinto y la escalera con tres peldaños verticales que ascendían hasta la abertura en el nuevo piso de piedra y barro superpuesto. En general, fueron exhumadas 16 tumbas, las que son ampliamente descritas (Bueno y Grieder 1979; Grieder y Bueno 1981; Grieder et al. 1988; Grieder 1997).

Las excavaciones en el Montículo Sur permitieron descubrir una serie de otros recintos curvados con nichitos trapezoides, banqueta que enmarca a un pequeño patio a desnivel y en cuyo centro se descubrió el horno con su ducto de ven- 


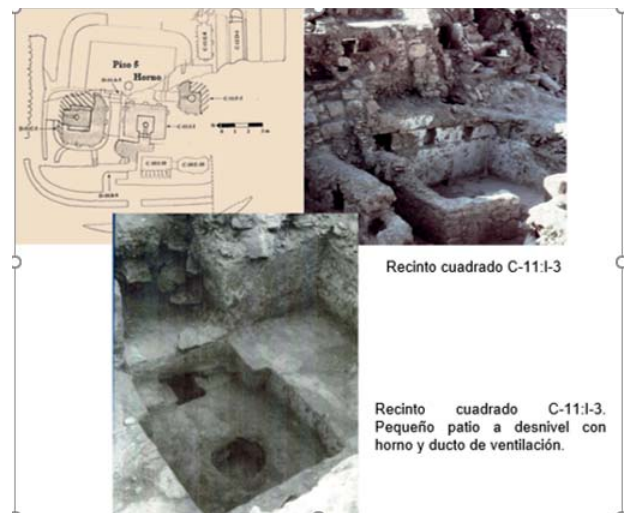

Figura 8. La Galgada: planta de los recintos excavados en el Montículo Sur C-11:I-3, D-11:C-3 y C-11:F-5. Tumba de las piedras verdes C-10:

E-10 con antecámara C10:I-10.

tilación dirigido hacia abajo del vano de acceso. Para el recinto curvado se obtuvo en 1978-79 varios fechados radiocarbónicos con su correspondiente calibración dendrocronológica: el recinto curvado construido en el nivel del piso 24 arrojó 2400 a.C.; el recinto cuadrado

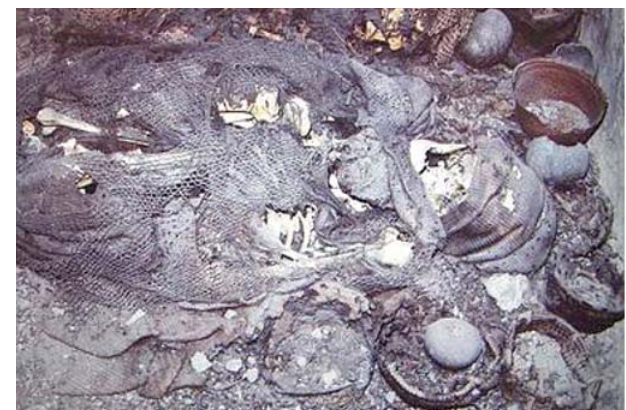

Figura 9. La Galgada: tumba F-2:B-12 ubicada al pie del lado sureste del Montículo Norte, donde fueron depuestos tres cadáveres identificados como un hombre y dos mujeres. Ofrendas de mates y canastas rodean las cabezas de los difuntos.
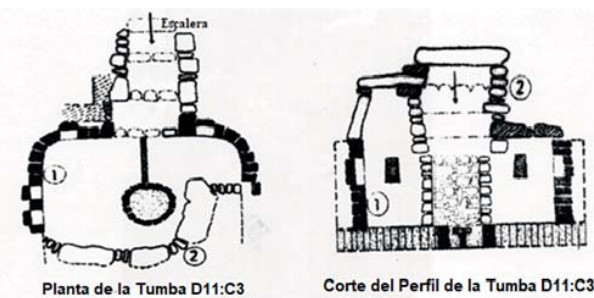

Figura 10. La Galgada: Montículo Sur. fue fechado en 2200 a.C. y otro curvado análogo al primero se considera similar en tiempo al primer fechado.

Una sucesión de rellenos y superposiciones permiten inferir y plantear una arquitectura en rápidos cambios, pero dentro de la persistencia del patrón arquitectónico descrito por lo menos durante 700 años en el contexto cronológico de $\mathrm{La}$ Galgada.

De hecho, las paredes del templo sur menor nunca alcanzaron mayor altura. Sólo se puede especular sobre el uso de los recintos ceremoniales con fogones. El material más común que se encuentra en sus pisos es pluma blanca, naranja, roja o verde. El único otro elemento que yacía directamente en el suelo de un recinto era la mitad inferior de un gran cuerno de venado. Estos materiales sugieren ceremonias en la arquitectura que conserva un pequeño patio a desnivel (ver recinto C-11:I-3). Tal vez los antiguos se sentaron en los niveles de la banqueta alrededor de los fogones para participar en sus rituales. En la mayoría de los recintos no hay suficiente espacio en el piso para bailar o ejecutar un ritual dramático escénico.

Alrededor del año 2500 a.C. el complejo del templo sur se estaba construyendo al lado del gran montículo norte. Durante los siguientes 700 años, se construyó recinto tras recinto con cinco aumentos sucesivos de superposiciones. La 
reutilización de los antiguos recintos ceremoniales para ser convertidos en tumbas es más claro en este ejemplar examinado. Cuando un recinto estaba a punto de ser abandonado, una pared de piedras grandes se adhirió $1.00 \mathrm{~m}$. para convertirla en cámara funeraria. Las piedras largas se colocaron como vigas del techo desde el nuevo muro hasta los antiguos muros del recinto precedente; luego, esta estructura mortuoria fue enterrada y el relleno de piedras menores permitió construir una escalera de tres peldaños conducente a la nueva superficie. Las cámaras funerarias subterráneas contenían de tres a cinco cadáveres; los que datan del período precerámico se extendieron sobre sus espaldas (Fig. 11); en cambio las deposiciones funerarias que transitaban al periodo de cerámica inicial (2000 a.C. - 1300 a.C.) se flexionaron en una posición sentada. En tiempos posteriores, tales tumbas se usaron ampliamente a lo largo de la costa oeste. Otras tumbas en La Galgada fueron construidas completamente nuevas en los espacios entre las paredes circundantes y entre los tres templos, las cuales se presentan en planta rectangular. Estos ejemplos, que se remontan a la última fase del período precerámico y al principio del período de cerámica inicial, se construyeron con piedras grandes sin forma o con formas canteadas. Parecen ser los prototipos de las llamadas galerías de los templos de Chavín en el período del Horizonte Temprano (1700 a.C. - 500 a.C.). Los templos de Chavín tienen conjuntos de pasillos o "galerías" pero no habitaciones reales en el interior. Las piedras canteadas utilizadas en las construcciones de la forma "galería”, se anticipan en el tiempo con las pequeñas galerías y tumbas de La Galgada.

Las tumbas han proporcionado la mayoría de los otros ejemplos de artes y oficios: especialmente joyería en piedra semipreciosa, un vaso de piedra decorado mediante incisiones (Fig. 12), morteros, cestas y textiles. Junto con fragmentos textiles precerámicos similares a la cueva Guitarrero, Huaca Prieta y algunos otros sitios, los fragmentos textiles de La Galgada proporcionan una evidencia importante del desarrollo temprano de la manufactura textil y vislumbran su alto logro artístico. Además del uso alternativo de fibras vegetales gruesas, las telas de La Galgada estaban hechas en algodón, planta presumiblemente cultivada en la localidad. La preferencia por el algodón es típica de todos los textiles precerámicos conocidos: las mantas y las bolsas son dos ejemplares identificables más comunes; cada espécimen producido en su propia técnica característica: las mantas por técnica entrelazado, las bolsas por técnica anillado. Cada uno de estos ejemplares tienen su rango de expresión técnica: el retorcido de trama se usa para manufacturar las mantas, pero se adapta bien a la forma de las bolsas; empero los arqueólogos han encontrado una serie de otras técnicas, como redes, enlazados, anudados, etc. Todas estas técnicas son comunes a todos los grupos textiles precerámicos conocidos.

De los fragmentos recuperados en las tumbas parece que los hombres llevaban una bolsa redonda a manera de un bolso asegurado con un lazo. Estas bolsas deben haber sido objetos de un orgullo especial, ya que son obras de arte: de las 
nueve bolsas cuyos diseños se pueden reconstruir de la manera más completa, las aves parecen haber sido en número de tres: dos parecían tener diseños de serpientes, dos tenían patrones circulares o curvilíneos y uno era rectilíneo, probablemente todos basados en algunas formas que se repetían y un fragmento mostraba una figura humana frontal con sus brazos convertidos en serpiente (Fig. 13). Esta última representación es probable que simbolice una deidad antropomorfa precerámica a juzgar por la posición frontal y los brazos-serpiente. La misma figura es frecuente en el arte arqueológico posterior, pero aún no es identificable por su nombre. Las bolsas no dan ninguna pista de su contenido original, excepto que se colocaron pequeñas canastas dentro de dichas bolsas en un entierro, además de cumplir la función de ajuar funerario.

Los fabricantes de las bolsas aprovecharon al máximo la libertad de diseño permitida por la técnica de anillado. Están pintados pero en ciertos casos el cambio de color es un cambio de hilo. Evidentemente, los antiguos tejedores compartieron, en su tiempo, el ideal estético de que la decoración debe estar integrada a la estructura de la tela. A pesar del tamaño pequeño y fragmentado de los textiles, los colores originales están bien conservados: rojo, amarillo, azul oscuro, así como los colores blanco y marrón se

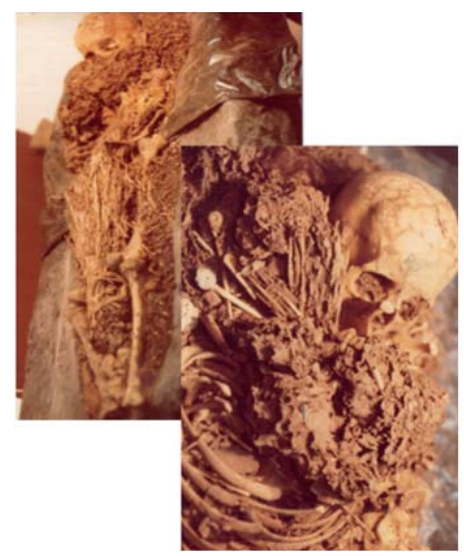

Figura 11. La Galgada, Montículo Sur: los cadáveres precerámicos tardíos fueron depuestos en posición decúbito dorsal extendidos (2,200 a.C.).

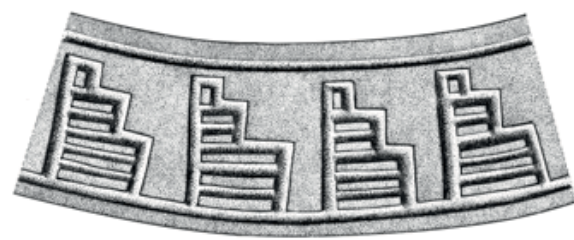

Figura 12. La Galgada, Montículo Sur: decoración mediante técnicas excavada e incisa, de un vaso lítico precerámico tardío.

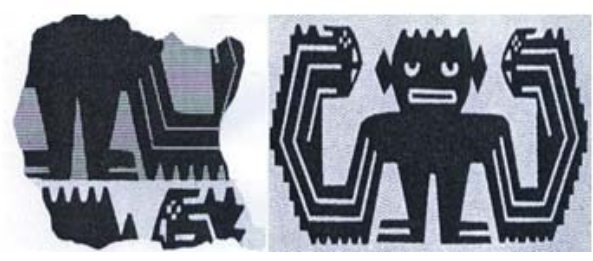

Figura 13. La Galgada: en el lado izquierdo se ilustra un fragmento de tela llana rota con motivo de personaje erguido en pintura negra. Al lado derecho se ilustra la recomposición del hombre robusto con sus brazos convertidos en serpientes y los ojos muestran la pupila vuelta hacia la conjuntiva. han registrado debido al color natural de los arbustos de algodones originarios. Los primeros textiles experimentales orientados a inventar el telar en La Galgada pertenecen al precerámico tardío del período precerámico; los textiles anteriores, que no fueron confeccionados en telar, a menudo deben haber empezado a utilizar un pequeño palo de soporte, pero en cada manipulación se ocupó de usar un solo hilo de urdimbre, o como máximo un par. 
Los textiles precerámicos recuperados de las tumbas presentan motivos pintados figurativos, figurativo-geométricos y geométricos: serpiente sonriente, serpiente bicéfala, aves, aves entrabadas (Fig. 14), aves entrabadas con serpiente, trapecios, el hombre con sus brazos convertidos en serpientes, etc.; lo figurativo-geométrico se asocia al tratamiento técnico lineal de los motivos; el repertorio geométrico representa rombos escalonados en oposición, rombos, bandas escaleradas interlocking, aspas sucesivas, círculos, líneas gruesas quebradas, trapecios, eses, flecha representando serpiente, etc., identificándose amarillos, rojos y negros para la combinación de colores, los mismos que se aprecian en el lomo de la serpiente caracolillo.

En la exhumación de las tumbas precerámicas de La Galgada hemos registrado notables textiles pre-telar pintados representando figuras de aves, aves entrabadas, aves-serpiente, la serpiente bicéfala, la serpiente, serpiente-ave entrabada, el hombre robusto con brazos convertidos en serpiente, el felino, peces, motivos geométricos (triángulos, círculos, aspas, etc.), plasmados en colores negro, negro sobre rojo, rojo sobre blanco, negro sobre amarillo, rojo sobre amarillo y marrón sobre blanco. Esta iconografía precerámica tardía representada en textiles está fuertemente asociada a los verdaderos textos gráficos de las representaciones en petroglifos de la quebrada Morín, los que en conjunto señalan orientación hacia el arte Chavín Temprano.

Muchos ejemplares textiles precerámicos conservan bien sus colores y las técnicas pre-textiles antecedentes son variadas: torzal, trenzado, anillado, entrelazado, entrabado, etc., que primero se manifestaron en la cestería de la cueva del Guitarrero (bolsas, canastas, petates, esteras), precedentes en la región acerca del desarrollo de la cestería precerámica antes del telar y del telar textil inicial en La Galgada. Según los hallazgos recuperados en este gran sitio, su gente descubrió la utilización del algodón de bellota blanca y bellota marrón, cuyas manipulaciones los condujo a inventar el hilo, sin el cual no hubiera sido posible la textilería conducente a confeccionar bolsas, telas llanas como soporte para pintar, cobijas, túnicas de vestir, etc.; además confeccionaron y usaron collares, pendientes, prendedores, prendedores de hueso con incrustaciones, lentejuelas de caparazones de moluscos, etc.

Asociadas a los templos descubrimos rocas con petroglifos cuyos diseños petroglíficos concuerdan con las figuraciones identificadas en los textiles precerámicos recuperados de las tumbas excavadas; tales representaciones petroglíficas son serpientes sonrientes, aves (Fig. 15) y figuraciones geométricas, las que están directamente en relación estilística con los petroglifos del gran sitio Los Cóndores, ubicado en la quebrada Morín de la margen derecha del río Chuquicara (Bueno Mendoza 1997), también con graficaciones de serpientes sonrientes, aves, felinos, peces, el hombre, mono, estrellas, etc.

Activos análisis contrastativos y contextuales evidencian cultura de hortelanos subsistenciales, complementados con actividades de cacería ampliadas a rutas recolectoras multirregionales hacia la selva y el mar, indicativos de actividades ma- 
crorregionales. Su ubicación territorial intermedia a esos ecosistemas extremos permitieron la orientación y dirección de los movimientos sociales. Los petroglifos subvenían necesidades de orden superestructura práctico para las actividades económicas de la gente, tener éxitos en sus acciones o librarse de la muerte.

Por otro lado, los hallazgos y estudios de los petroglifos Morín-La Galgada, por atención a sus notables motivos de similaridades técnico/figurativas con los contextos precerámicos funerarios del complejo monumental $\mathrm{La}$ Galgada y a la iconografía de los textiles precerámicos exhumados de las tumbas excavadas en la Pirámide Sur, son indicativas de coetaneidad cronológica (2200 a.C.). Se ha publicado los fechados radiocarbónicos obtenidos para La Galgada (Grieder et al. 1988).

En conjunto acotamos que el arte de las formaciones sociales tempranas de vida campestre y centros ceremoniales precerámicos en desarrollo,

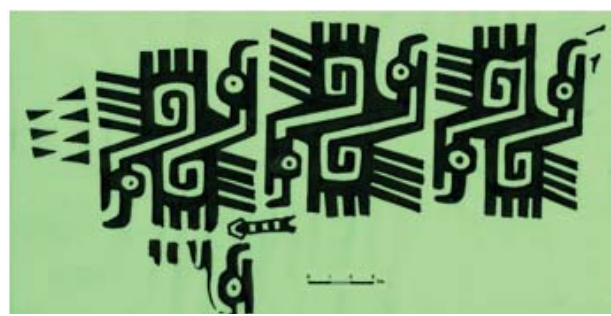

Figura 14. La Galgada: (tumba C10:E10 de las piedras verdes); aves entrabadas representadas en un fragmento de textil precerámico tardío.

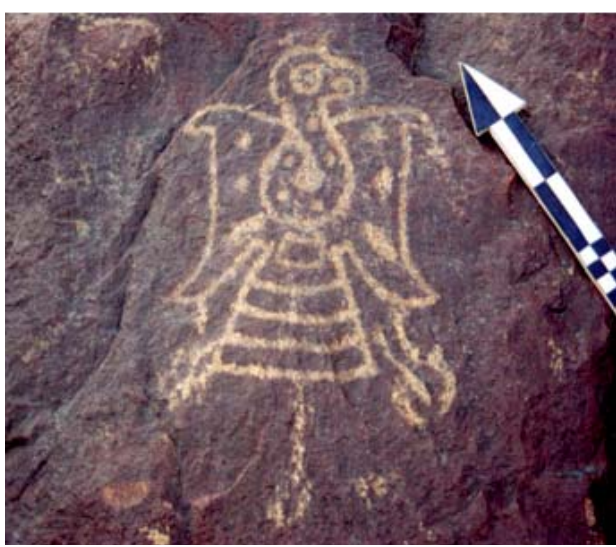

Figura 15. La Galgada: Petroglifo mostrando un cóndor con alas estilizadas, gran cola extendida y patas al ristre. Notar el diseño gráfico para plasmar el cuello y cabeza del voltúrido donde destaca su gran ojo abierto y su pico en gancho. como en este caso, estuvo basado en la agudeza de los sentidos, tuvo carácter vitalista y se nutrió de las relaciones hombre/territorio. No es un producto secundario del desarrollo social, sino una de las creaciones genuinas conformantes del circuito social. Por eso el arte petroglífico estudiado, a pesar de ser producción individual, emerge en el regazo social, del cual toma sus temas para expresar su ideología y cultura; de allí que el arte rupestre en general sea un lenguaje gráfico expresivo de formas empíricas de conocimiento e implica un gran nivel de reflexión otorgante de mensajes que son verdaderas visiones espontáneas sobre aquellas realidades.

Así, el arte rupestre constituye verdaderos textos gráficos autoinformativos que se convierten en soportes de su vitalidad, comprensión del microcosmos en relación a la amplitud del macrocosmos: les insuflaría ánimo para descubrirse creativos e intérpretes de su propia realidad existencial; ellos existían para luego pensar y después graficarlo. Tal graficación permitió auto-otorgarse un sentido existencial, pues la proyección de su memoria está en nosotros al conocer el valor artístico y documental de sus textos petroglíficos. 
Las imágenes petroglíficas registradas son expresiones gráficas donde representan al hombre en su ecosistema natural, impactando sobre los animales, pero también dando importancia a sus acciones, que por la vía de ocurrir de lo natural a lo cultural descubre también las transiciones hacia los mitos, los símbolos y las metáforas de valor sígnico.

En 1979, se descubrieron cinco discos (Fig. 16) confeccionados en concha marina amarrados a un fragmento de tela llana en el atrio alto céntrico del templo norte, en un nivel fechado con radiocarbono de $3540 \pm 50$ BP. Cuando se calibró por dendrocronología a años calendario se obtuvo la fecha de entre 2140 y 1860 a.C. Esta fecha es de especial interés porque cuatro de los discos están decorados con diseños que muestran la transición del estilo de arte precerámico al estilo de Chavín. El poderoso y extendido estilo Chavín dominó el arte andino desde su gran centro ceremonial Chavín de Huántar, en las montañas, a 160 kilómetros al sur de La Galgada, desde aproximadamente 1700 á 300 a.C. La presencia de imágenes al estilo Chavín en un nivel tan temprano sugiere un desarrollo anterior y más largo en el tiempo del estilo Chavín no previsto anteriormente. El más sencillo de los discos originales (Fig. 16, a) carece de decoración. El disco (Fig. 16, b) representa cara de un hombre anciano que muestra la nariz con tratamiento felinesco y boca chavinense. El tercer ejemplar (Fig. 16, c) está confeccionado en concha blanca, llevando cuatro cabezas de ave en el borde: tiene los ojos incrustados con piedra roja o verde indistintamente. El cuarto disco (Fig. 16, d) de aspecto iridiscente presenta un diseño de cuatro bocas y en las mismas induce a ver cuatro felinos en descanso, además lleva inscritas cuatro cabezas de ave. El quinto disco (Fig. 16, e) de figuración geometrista está basado en la figura de un ave rapaz con pico en forma de gancho; se nota pintura roja en las incisiones; además induce a ver cuatro hocicos llevando lenguas bífidas serpentiformes céntricas en cada una de ellas. En conjunto, los tres discos decorados a base de motivos Chavín sugieren que el arte de los andes centrales se desarrolló desde el precerámico tardío al estilo Chavín más rápidamente de lo que se pensaba anteriormente. Mientras que los discos (a) y (c) son precerámicos con su aspecto de superficies lisas tamaño pequeño y cabezas sencillas de aves e incrustaciones con piedras de colores en los ojos, los discos (b), (d) y (e) comienzan a mostrar las características de Chavín en su angularidad figurativa abstraccionista y la especificación gráfica de un pico en forma de gancho. La presencia de estos discos juntos con los del período precerámico implica la existencia del estilo maduro de Chavín antes de 1800 a.C. En conjunto los discos decorados sugieren que el arte pre-Chavín transitó desde el estilo de arte precerámico al estilo Chavín más temprano de lo que se pensaba anteriormente.

Una sucesión de rellenos y superposiciones constructivas permiten inferir una arquitectura en rápidos cambios, pero dentro de la persistencia del patrón arquitectónico descrito por lo menos durante mil años y un arte figurativo en fuertes procesos de cambio. 
Indudablemente hay una relación tipológica entre los constructores de galerías arquitectónicas y la conversión de recintos en tumbas abotelladas. A los recintos blancos con horno y nichitos trapezoides precerámicos siguieron los constructores de tumbas abotelladas igualmente precerámicas tardías, a los cuales sucedieron generaciones transitivas de constructores en superficie, otorgantes de nueva imagen formal para la arquitectura del Montículo Norte; diferencialmente, notamos variación morfológica pero dentro de la concepción precedente en el Montículo Sur: cámaras rectangulares con cubiertas de lajas planas tendidas horizontales o con falsa bóveda, como extensión y avance del recinto cuadrado C-11:I-3 de ángulos rectilineales; aparecen pasadizos cortos y los muros envolventes 3,2,1 los cuales permitieron elevar el Montículo Sur hasta los 6 metros de verticalidad.

Tales nexos tipológicos pueden

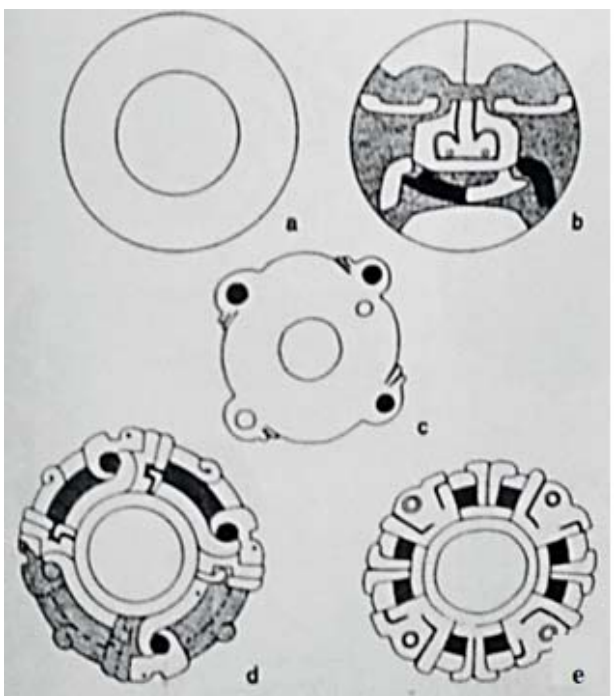

Figura 16. La Galgada, Montículo Norte; pequeñas placas confeccionadas en concha Spondylus: a) placa circular simple; b) cara de hombre anciano chavinesco; c) placa circular figurando cuatro aves; d) placa circular figurando cuatro hocicos felinoides chavinenses con colmillos en la comisura respectiva; e) plaqueta circular figurativa representando cuatro hocicos con lengua bífida entramados a cuatro cabezas de aves. Estos motivos son relacionados con Chavín Temprano (1800-1700 a.C.). probarse por la evidente imbricación arquitectónica, el replanteamiento conceptual de formas y elementos que acusan patrón de continuidad estructural entre los períodos y evolución iconográfica del arte precedente hacia una nueva y alta complejización en presencia de cerámica inicial.

En la superficie alta del Montículo Norte se perfilaron los lineamientos para plantear una nueva morfología arquitectónica de este monumento con caracteres rectilineales.

La conceptualización de una morfología arquitectónica en "U” para innovar la imagen formal del Montículo Norte por medio de rellenos y adiciones constructivas, puede considerarse como avance de cambios drásticos en la arquitectura de evolución local, la que pasa rápidamente de las tumbas soterradas y galerías cortas rectilíneas hacia las formas en herraje a cielo abierto (planta "U” alta).

La "U" está constituida por dos brazos laterales -derecho e izquierdo- y su correspondiente depresión central o atrio alto. A partir del plano del atrio alto, el brazo derecho tiene $3 \mathrm{~m}$. de elevación y $5 \mathrm{~m}$. de verticalidad el izquierdo (Fig. 17). Ambos brazos tienen ventanas de ingreso a galerías subyacentes. Se ha detectado el ingreso a corta galería ubicada en el flanco externo de la esquina curvada noroeste 
a la actualidad rellena con grandes piedras. Igualmente se precisa descubrimiento del ingreso a otra galería aun no explorada subyacente debajo de los rellenos conformantes del brazo izquierdo de la "U".

En el atrio se ha descubierto cimentaciones de plataforma escalonada (tres escalones con $40 \mathrm{~cm}$ de altura) y pisos a base de rellenos delgados. Los brazos norte derecho e izquierdo sur fueron concepcionados en forma de plataformas alargadas de disposición paralela hacia el oeste, cuya separación central es su atrio. Una plataforma rectangular de disposición transversa norte-sur se extiende en el centro posterior del herraje con respecto a los brazos laterales, constituyendo la base de la "U" abierta al oeste. Las esquinas de la "U" son rectilineales, y en general, se empieza a implantar la línea recta y el plano como elementos morfológicos funcionantes en esta nueva arquitectura de transición, salvo el hecho de que los muros curvados precerámicos siguieron funcionando para las esquinas externas conformantes de la imagen formal última.

En el centro superficial de la base este de la "U" se excavó una escalera a base de piedras semitalladas, todavía experimentalmente (Fig. 18), pero significativas desde el punto de vista técnico.

En el brazo sur, parte delantera y como descendiendo al atrio fue descubierta otra corta escalera, pero de piedras simplemente canteadas. Ambas funcionaron coetáneamente y se asocian a las innovaciones del atrio en " $U$ ". La arquitectura "U”" enterró definitivamente a la arquitectura anterior de recintos precerámicos curvados.

Así pues, en La Galgada puede seguirse la evolución arquitectural desde las formas cercadas, sencillas, pasando por la conceptualización del espacio interno significativo, hasta alcanzar el monumental volumen piramidal. Su investigación implica observación empírica contrastada de constantes, elementos de cambio y los cambios mismos. Por tanto, en esta arquitectura arqueológica tales cambios explícanse analizando los procesos de diferenciación socio-culturales. Con relación a tales aseveraciones, precisamos que en La Galgada los edificios en estudio plantean un uso múltiple asociado a cada etapa de modificación y/o adiciones arquitectónicas, puesto que cada morfología favorece y permite alcanzar la impasibilidad mística, y en consecuencia, asumir "prestigios" superestructurales; concluyéndose que tal sitio y edificios componentes no son el resultado unilateral de determinismos físicos, sino de las relaciones significativas socioculturales que demandaron los cambios.

En consecuencia, es posible plantear una continuidad arquitectónica precéramica regional estable en base a una población frecuentemente alternativa, cuyos recambios generacionales fueron siempre portadores de la tradición cultural ancestral. La tecnología tardía constructiva de que se dispuso, fue en realidad importante como modificante de las morfologías precedentes.

La localización en el territorio es también seleccionada en base a modelos culturales más que a determinantes físicas, aunque el relieve impone ciertas servi- 
dumbres y regula la creación empírica de las edificaciones según la imagen del entorno: las colinas elevadas emanan mayores poderes mágico-religiosos que las faldas bajas, incluso débese haber otorgado significado divino terrígeno a algunas figuraciones evidentes perfiladas en sus altas cumbres; actúan factores mitológicos en tomo a reiterativas frecuencias de fuerzas naturales propiciadoras del apego mítico al lugar del emplazamiento templario; además, el asentamiento de los templos en las entrañas de un profundo cañón, permitió visibilidad de fijo reciclaje para el desarrollo de la observación astral destinada a obtener fórmulas de magnitudes y orientación.

Los templos alineados paralelos al río de aguas permanentes es disposición importante para el análisis: agua adyacente, montaña mítico-mágica figurativa en las cumbres cerriles, fuego en los hornos de los recintos sacros y limpio cielo nocturno plagado de astros, modelarían una parafernalia compleja, (¿en torno al fuego?), pues es alertante el hecho de que las vertientes rituales-

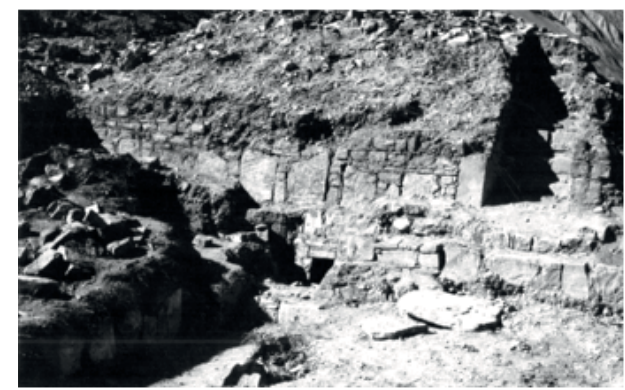

Figura 17. La Galgada, Montículo Norte: el brazo izquierdo alto de la "U" excavado en la cumbre de la pirámide norte; notar adelante la escalera de ascenso y en la base céntrica la ventana de entrada a la galería interior.

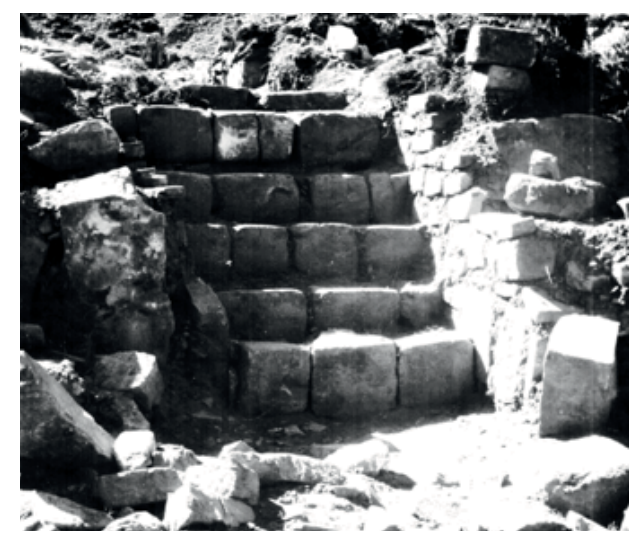

Figura 18. La Galgada, Montículo Norte: escalera ubicada al centro este de la "U" mostrando en forma lateral el comienzo del brazo izquierdo que se proyecta hacia el oeste. ceremoniales más evidentes connotan su presencia en todos los recintos sacros y/o necróticos del sitio.

Como la cultura precerámica tardía tuvo estilo definido dentro de diversidad expresiva e innovación restringida a regiones de desarrollo, los edificios religioso-ceremoniales adquirieron superlativo valor simbólico en contraste a las precarias viviendas asociadas, debido a que la especialización religiosa condujo a originar celectividades complejas y precisar al conductor especialista "inteligente”: los cultos, el rito y las ceremonias originaron y produjeron trabajo, técnicas, organización y la diferenciación de ocupaciones.

Para el estado actual de las investigaciones en La Galgada, aseguramos que pisos blancos, hornos céntricos con ducto de ventilación inscrito en pequeño patio cuadrado a desnivel, perfiles murarios blancos, pestañas de retiro para connotar la presencia de nichitos trapezoides y un solo vano de ingreso, configuran equipa- 
miento físico compartido por los sitios de La Galgada y Kotosh de la Fase Mito, territorio entre Huánuco y Ancash. Empero, La Galgada según sus evidencias, es de mayor antigüedad.

Las proposiciones manifiestas revelan el desarrollo de niveles culturales en rápidas transformaciones y que a través de cambios sucesivos fue alcanzándose expresiones arquitectónicas, textiles, iconográficas, talla lítica y contextos sociales de la mayor complejidad, permitiéndonos tener la seguridad de estar tratando en La Galgada con identificación de la cultura “abuela” de Chavín.

La aparición alfarera inicial en el sitio ha sido fechada hacia los 2100 a.C. á 1850 a.C. (ver: Grieder et al. 1988: 69).

De lo escrito se concluye que en La Galgada se asiste a una tradición arquitectónica precerámica de larga duración en el tiempo (2700-2000 a.C.). A los recintos curvados originarios con nichitos, patio a desnivel y horno inscrito con ventilador, le sucede la morfología cuadrada/rectangular de similar concepción interna, los que al ser abandonados como núcleos de interés, fueron convertidos en tumbas con falsa bóveda a las que se tenía acceso por galerías de corto trayecto (3 á 5 metros promedio), modificando los conceptos originarios por medio de adiciones constructivas, rellenos, superposición de pisos y nuevos recintos. La relación tipológica puede probarse por la evidente imbricación arquitectónica de los elementos formales que acusan patrón de continuidad estructural entre las fases, planteándose que los cambios arquitectónicos fueron mínimos, ya que las morfologías definidas se repiten en diferentes sectores y niveles hasta la introducción de la alfarería en el sitio (1850 a.C.), al mismo tiempo que se concreta la presencia de Chavín Temprano.

Los templos sucesivos fueron técnicamente edificados mediante labores de construcción, rellenos, reconstrucciones, modificaciones, renovaciones y adiciones arquitectónicas. Las técnicas constructivas desarrolladas es experiencia que permitió prolongar las morfologías precedentes orientadas hacia las innovaciones.

Hay una diferencia abismal entre la masa, elevación y elaborada arquitecturación de los montículos y lo precario de los habitáculos asociados: alrededor de los templos se han detectado unos 50 habitáculos de planta ovalada, circular y misceláneas; fueron construidas excavando los mantos de cascajo para luego revestirlas con piedras medianas de cerro y/o cantos rodados abundantes en el lecho del río para dejar un interior de 2 metros por 1,5 metros promedio.

Los templos y habitáculos asociados son limpios, pues casi no hay ceniza ni basura arqueológica: esto quiere decir que la vida cotidiana transcurría fuera del área de los montículos y que tales habitáculos funcionaron como pernoctorios.

El análisis general permite inferir organización social a base de la familia nucleada de cuyo seno emerge la conducción elitista. Los templos funcionaron como atractivos gregarios, sede de eventos especializados, cuyas actividades ceremoniales (complicado ritual mortuorio, etc.) permitieron diferenciarse al conductor 
social temprano por su dedicación a comprender e interpretar los fenómenos naturales, observar los astros, ciertos ciclos biológicos sencillos y determinar sobre aspectos del colectivo dentro de sus parámetros culturales.

Así, en La Galgada, los edificios en estudio plantean un uso múltiple relacionado a cada etapa de modificación o adiciones arquitectónicas puesto que cada recinto permite y favorece alcanzar la impasibilidad mística. El estudio del comportamiento ceremonial y simbólico de la gente precerámica del sitio, en relación contrastante con otras formaciones sociales coetáneas debe explicar las sucesivas modificaciones y/o adiciones físicas, valuando incluso la categoría simbólica de cada recinto. Por tanto, la arquitectura en rápidos cambios explicaríase analizando los procesos de diferenciación socio-culturales orientados a las innovaciones y transformaciones físicas de los templos.

Nuestras investigaciones en La Galgada permiten proseguir planteando algunas hipótesis generales para el asunto tratado, debido a que se trata de una arquitectura adaptada al clima local, a la economía de intercambios regionales, actividades trashumantes de altura, a los materiales disponibles y a la cultura del contexto social en dinámica de cambios.

Por la costa de Ancash, la forma arquitectónica en planta cuadrada con esquinas curvadas al exterior e interior se encuentra también en el valle de Casma: Sechín Bajo, Cerro Sechín y Moxeque: en Sechín Bajo es curvado el edificio más antiguo del sitio; Cerro Sechín muestra que todo el plan del edificio central de barro que despliega la planta cuadrada con esquinas curvadas tanto el recinto de los felinos como su cerco externo a base de piedras grabadas mayores y menores, todas figurativas antropomorfas.

Del procesamiento de datos arqueológicos reseñados se concluye que la arquitectura precerámica a base de plataformas con pozo ceremonial, pirámides y pirámides rematadas en la morfología “U”, es más antigua en la cuenca del río Chuquicara, comparten relaciones tipológico-estilísticas con arquitecturas similares del norte medio entre 2700 a.C. a 2000 a.C. y entre 2000 á 1000 a.C. el pozo ceremonial se incorpora en la Costa Central a los conjuntos de planta en "U" precerámicos y cerámico-iniciales, mientras que por la sierra interandina el pozo ceremonial y la morfología "U” siguió su proceso de difusión para cruzar la cordillera blanca e instalarse entre los ríos Mosna y Wacheqsa, alcanzando su máxima expresión en el Templo "U” de Chavín, además que todo el asiento despliega el planteamiento distributivo espacial en "U" orientado hacia el este. Finalmente, la llamada "Plaza Circular" inscrita en el atrio "U” del Viejo Templo del dios Guari, es también el desarrollo máximo del antiguo pozo ceremonial precerámico, que lo encontramos incorporado como plaza al contexto Chavín ocupando el centro del rectángulo entre los brazos de la "U” del templo más antiguo del sitio Chavín de Huántar. 


\section{Referencias citadas}

Alva, Walter

1986a Investigaciones en el Complejo Formativo con Arquitectura Monumental de Purulén (Informe Preliminar). Beiträge zur Allgemeinen und Vergleichenden Archäologie 8: 238-300. Mainz.

1986a Excavaciones en el Santuario del Tiempo del Formativo Udima-Poroporo en la sierra norte del Perú. Beiträge zur Allgemeinen und Vergleichenden Archäologie 8: 301-352. Mainz.

Bird, Junius B.

1963 Preceramic art from Huaca Prieta, Chicama Valley. Ñawpa Pacha 1:29

Bischof, Henning - 34. Berkeley.

1988 Los Relieves de Barro de Cerro Sechín. Boletín de Lima 55: 59-68. Lima.

1994 Toward the definition of Pre-Early Chavin Art Styles in Peru. Andean Past 4: 169-228.

Bonavía, Duccio

1982 Precerámico peruano. Los Gavilanes: mar, desierto y oasis en la historia del hombre. Corporación Financiera de Desarrollo S.A. e Instituto Arqueológico Alemán (edits.), Lima, 522 pp. +7 mapas.

Bueno Mendoza, Alberto

1970-1971 Arqueología Peruana. Sechín: síntesis y evaluación crítica del problema. Boletín Bibliográfico de Antropología Americana. Instituto Panamericano de Geografía e Historia, México, Vol. 33/34: 201-221.

1977 Materiales para el Estudio de la Arquitectura Arqueológica. Edit. Universo, Lima, 124 pp.

1983 Arquitectura y Sociedad pre-Chavín en los Andes Centrales. Boletín de Antropología Americana 6: 119 - 140. México.

1997a Los Cóndores en La Galgada: Petroglifos como Textos Gráficos. Espacio 36: 54 - 61. Lima.

1997b El Proceso Precerámico y los Primeros Centros Urbanos. En: Actas y Trabajos del XI Congreso Peruano del Hombre y la Cultura Andina “Augusto Cardich”, editado por Hernan Amat Olzabal y Luis Guzman Palomino, Tomo I, pp. 253-290, Lima.

2006 Petroglifos en la Quebrada Morín y La Galgada de los Textos Gráficos al Mito Etiológico. Investigaciones Sociales 17: 77 - 90. Instituto de Investigaciones Sociales, Universidad Nacional Mayor de San Marcos, Lima.

Bueno, Alberto y Lorenzo Samaniego Román

1969 Hallazgos Recientes en Sechín. Amaru 11: 31-38. Universidad Nacional de Ingeniería, Lima. 
Bueno, Alberto y Terence Grieder

1979 Arquitectura Precerámica en la Sierra Norte. Espacio 1(5): 48 - 55. Lima.

1980 La Galgada: Nueva Clave para la Arqueología Andina. Espacio 9(9): 48 - 55. Lima.

1981 Arte y Cultura Precerámica. Espacio 10(3): 50 - 70. Lima.

Bueno Mendoza, Alberto, Pieter van Dalen Luna, Yuri Cavero Palomino, Hans Grados Rodríguez y Roy J. Lazo Pérez (Ediores)

2015 Actas de Ponencias del V Simposio Nacional de Arte Rupestre - SINAR. “Eloy Linares Málaga”. UNMSM, Lima, 395 pp.

Burger, Richard L.

1998 Excavaciones en Chavín de Huántar. Fondo Editorial de la Pontificia Universidad Católica del Perú, Lima

Damp, Jonathan

1988 La primera ocupación Valdivia de Real Alto: Patrones Económicos, Arquitectónicos e Ideológicos. Escuela Politécnica del Litoral (ESPOL), Corporación Editora Nacional, Guayaquil. Biblioteca Ecuatoriana de Arqueología, Vol. 3, 148 pp.

Fuchs, Peter

1997 Nuevos Datos Arqueométricos para la Historia de la Ocupación de Cerro Sechín. Período Lítico al Formativo. En: Archeologica Peruana, ํ2: Arquitectura y Civilización en los Andes Prehispánicos, editado por Elizabeth Bonnier y Hennig Bischof, pp. 145-162. Sociedad Arqueológica Peruano-Alemana. Reiss-Museum, Mannheim.

Fux, Peter (Editor)

2015 Chavín. Peter Fux: Editor General. Pub. Museo de Arte de Lima (MALI), Compañía Minera Antamina S.A., Lima, 412 pp.

Grieder, Terence y Alberto Bueno Mendoza

1981 La Galgada, Peru Beffore Pottery”. Archaeology 34(2): 45-51.

1985 Ceremonial Architecture at La Galgada. En: Early Ceremonial Architecture in the Andes. Conference at Dumbarton Oaks 1982, Editado por Christopher Donnan, pp. 93-109. Dumbarton Oaks Research Library and Collection, Washington.

Grieder, Terence, Alberto Bueno Mendoza, C. Earle Smith y Robert Malina

1988 La Galgada, Peru. A Preceramic Culture in Transition. University of Texas press, Austin-Texas, 282 pp.

RAVINES, Rogger (compilador)

2012b Chavín Retrospectivo. Antología Introductoria. Boletín de Lima 34(169/170): 19-102, Año 34, Lima.

Samaniego, Lorenzo, Enrique Vergara y Henning Bischof

1985 New Evidence on Cerro Sechin, Casma Valley, Peru. En: Early Cere- 
monial Architecture in the Andes, editado por Christopher Donnan, pp. 165-190. Dumbarton Oaks, Washington DC.

Tello, Julio C.

1943 Discovery of Chavin Culture in Peru. American Antiquity 9(1): 135160.

1960 Chavín. Cultura Matriz de la Civilización Andina. Pub. Antropológica del Archivo “Julio C. Tello” de la Universidad Nacional Mayor de San Marcos, Vol. II, Lima, 425 pp. 